Г. АШКИНАЗИ, Л. ЗОЛОТАРЕВСКИИ, В. ТИМОФЕЕВ, Л. МАЗО, М. ШУЛЬГА, В. ВОИТОВИЧ, М. ТАГАСААР, Н. ОРЕНШТЕИН, Х.ЮИРИКЕ, В. ЧЕЛНОКОВ

\title{
СИЛОВЫЕ ВЫСОКОТЕМПЕРАТУРНЫЕ ВЫСОКОЧАСТОТНЫЕ ПРИБОРЫ НА ОСНОВЕ АРСЕНИДА ГАЛЛИЯ
}

Результатом интенсивных теоретических, экспериментальных и технологических исследований последних лет явилось создание впервые в СССР малогабаритных высокотемпературных высокочастотных силовых полупроводниковых приборов на основе арсенида галлия $\left[{ }^{1-5}\right]$. В данной работе приводятся основные параметры и характеристики разработанных макетных образцов диодов и тиристоров на основе арсенида галлия, а также результаты исследований по созданию диодов Шоттки. Помимо этого в работе приводятся результаты исследований диффузионной длины электронов в нелегированном $P$-арсениде галлия, образующемся при выращивании нелегированных слоев на подложках любого типа проводимости $\left[{ }^{6}\right]$. Рассмотрены также результаты исследований, направленных на выяснение причины образования $P$-области при выращивании нелегированных слоев арсенида галлия из раствора-расплава.

1. Диоды. Основным технологическим методом создания макетных образцов диодов на основе арсенида галлия (ДАГ) является метод выращивания из раствора-расплава. На основе выращенных $P^{+}-P-N-N^{+}$. структур создаются выпрямительные элементы диаметром от 7 до 15 мм. Альтернативным методом создания диодной структуры является метод выращивания из паровой фазы, например, в системе $\mathrm{Ga}-\mathrm{AsCl}_{3}-\mathrm{H}_{2}$. Данный метод создания диодных структур также может быть применен при изготовлении ДАГ.

Макетные образцы ДАГ имеют следующие параметры:

средний прямой ток

обратное напряжение при температуре $280^{\circ} \mathrm{C}$ максимальная температура $P-N$-перехода . время обратного восстановления прямое падение напряжения

$$
\begin{gathered}
25-320 \mathrm{~A} \\
100-600 \mathrm{~B} \\
280{ }^{\circ} \mathrm{C} \\
0,1-0,3 \text { м кс }
\end{gathered}
$$$$
\text { менее } 2 \text { В }
$$

2. Тиристоры. Дальнейшим развитием работ по созданию силовых полупроводниковых приборов (СПП) на основе арсенида галлия явилось создание макетных образцов силовых тиристоров на основе арсенида галлия (ТАГ).

Основным технологическим методом создания тиристорной структуры является выращивание из раствора-расплава триодной $N^{+}-P-N$-структуры $\left[{ }^{6}\right]$ с последующим созданием $P^{+}$-эмиттера. Управляющий электрод создается методом фотолитографии и прецезионного локального травления. Диаметры тиристорных элементов аналогичны диаметрам ДАГ.

Конструктивно ТАГ выполняется в штыревом варианте. 
Основные парамерты макетных образцов ТАГ:

напряжение переключения

до 300 В

средний прямой ток

до $100 \mathrm{~A}$

максимальная температура $P-N$-перехода время выключения

свыше $200^{\circ} \mathrm{C}$

$0,8-2$ мкс

При создании ТАГ основная триодная $N^{+}-P-N$-структура создается в едином технологическом цикле выращивания из раствора-расплава. При этом используется тот факт, что при выращивании нелегированного слоя арсенида галлия из раствора-расплава на подложках любого типа проводимости (в том числе и на $N^{+}-\mathrm{GaAs}$ ) первоначально вырастает слой $P$-типа, а в дальнейшем нарастает слой $N$-типа проводимости $\left[{ }^{6}\right]$. Причины и механизм образования слоя $P$-типа в настоящее время до конца не ясны.

Исследованиям механизма фонового легирования посвящено большое количество работ (см. например, обзор $\left.\left[{ }^{7}\right]\right)$.

В данной работе нами исследовались спектры фотолюминесценции (ФЛ) нелегированного арсенида галлия $P$ - и $N$-типа и изменение этих спектров при термообработке. Для исключения влияния подложки изучались спектры как $P^{+}-P-N$-структур, наращенных на $P+$-подложке, легированной цинком до концентрации $10^{19} \mathrm{~cm}^{-3}$, так и $N^{+}-P-N$-структур, наращенных на $N^{+}$-подложке, легированной оловом до концентрации $10^{18} \mathrm{~cm}^{-3}$. Сравнение этих спектров позволяет исключить влияние подложки.

Для исследования влияния термообработки образцы нагревали в среде водорода до температуры $950^{\circ} \mathrm{C}$. Скорость нагрева $4-5 \mathrm{~K} /$ мин, выдержка - 5 ч с медленным (1 K/мин) охлаждением.

Возбуждение ФЛ осуществлялось $(\mathrm{He}-\mathrm{Ne}): \mathrm{Cd}$-лазером с длиной волны 441,6 нм. Разрешающая способность фотоэлектронного умножителя (ФЭУ) определяла область исследуемых энергий в диапазоне $1,2-1,6$ эВ. Точность измерения энергии составляла \pm 2 мэВ, диаметр зонда был равен 20 мкм.

Қак показывает рис. 1, типичный спектр краевого излучения нелегированного $N$-слоя при $87 \mathrm{~K}$ имеет две полосы излучения: одну с энергией 1,507 эВ и другую менее интенсивную с энергией 1,487 эВ. Из имеющихся в литературе данных по исследованию излучательной рекомбинации в нелегированном $N$-арсениде галлия следует, что полоса 1,507 эВ соответствует переходу электронов с мелких донорных уровней кремния в валентную зону '[8]. Присутствие Si в эпитаксиальном слое связано с особенностями эпитаксиального процесса, рассмотренными в [ $\left.{ }^{6}\right]$. Полуширина полосы 1,507 эВ составляет 18 мэВ, что составляет примерно $2 \kappa T$. Такую же полуширину имеет и полоса 1,487 эВ, причем ее интенсивность возрастает по мере перехода к $P$-слою и $P^{+}$-подложке

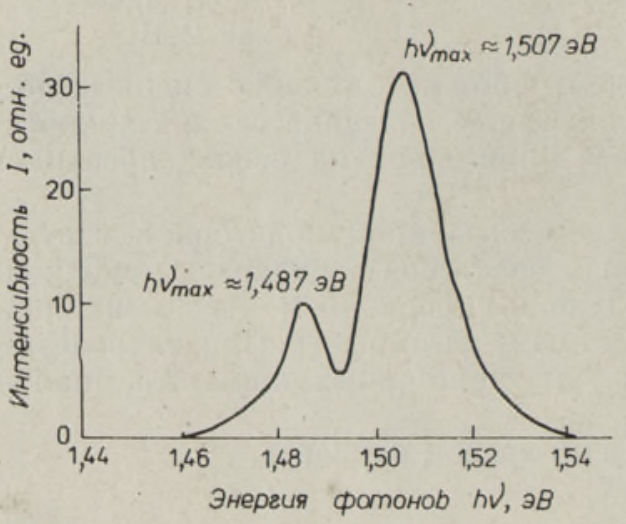
$P^{+}-P-N$-структуры. В $P$-слое, как правило, еще доминирует пик 1,507 эВ, однако в области перехода $P^{+}$-подложка-эпитаксиальный слой интенсивность пика с энергией 1,487 эВ резко возрастает и превышает интенсивность пика 1,507 эВ.

Рис. 1. Спектр краевого излучения нелегированного $N-\mathrm{GaAs}$ диодной $P+-P-N$ структуры при $87 \mathrm{~K}\left(P^{+}-\right.$подложка легирована цинком). 
Что же касается спектров ФЛ, снятых с образцов, подвергнутых термообработке, то картина полос излучения и распределение их интенсивностей относительно друг друга в разных областях $P^{+}-P-N$-структуры та же, что и в случае неотожженных образцов, за исключением того факта, что интенсивность рекомбинационного излучения из эпитаксиального слоя уменьшается примерно в 2 раза. Концентрация основных носителей заряда в эпитаксиальных слоях после термообработки остается прежней, и так как наиболее вероятно, что во время отжига происходит нарушение стехиометрии за счет увеличения числа мышьяковых вакансий (испарение мышьяка фиксировали взвешиванием с точностью 0,1 мг до и после термообработки), то представляется возможным предположить, что собственный дефект решетки $V_{\text {As }}$ является тушителем люминесценции. Подробный анализ спектров, полученных со структур, наращенных на подложках $P^{+}$- и $N^{+}$-типа позволяет сделать вывод, что имеется наложение двух пиков излучения: переход акцепторный уровень цинка - зона проводимости и переход акцепторный уровень кремния зона проводимости.

Исходя из вышесказанного можно сделать следующие заключения.

1. Нелегированные области эпитаксиального $N-\mathrm{GaAs}$ определяются наличием основной фоновой примеси - кремния в узлах галлиевой подрешетки.

2. Акцепторные центры, ответственные за образование $P$-слоя, повидимому, также участвуют в рекомбинационном излучении, но обладают значительно меньшим сечением захвата, чем акцепторные уровни $\mathrm{Zn}$, и в спектрах фотолюминесценции при температуре жидкого азота не проявляются на фоне излучения через уровни цинка. Вероятно, акцепторные центры, ответственные за образование $P$-слоя, связаны с наличием $\mathrm{Si}$ в узлах подрешетки мышьяка, т. е. мы имеем дело с проявлением свойств кремния, как амфотерной примеси в арсениде галлия.

Взаимосвязь образования $P$-области при наращивании $\mathrm{N}^{+}-\mathrm{P}-\mathrm{N}$ структур методом выращивания из раствора-расплава с вхождением кремния в узлы подрешетки мышьяка указывает на возможность управления этим процессом путем изменения условий вхождения кремния в узлы подрешеток галлия и мышьяка, например, путем изменения парциального давления мышьяка в течение процесса выращивания.

Одновременно с излучением спектров фотолюминесценции нелегированного $P-\mathrm{GaAs}$ изучались и элетрофизические параметры этой области и в первую очередь диффузионная длина электронов.

В настоящее время достаточно хорошо изучена диффузионная длина дырок в $N$ - GaAs при различных уровнях легирования $\left[{ }^{9,10}\right]$. Однако диффузионная длина электронов в $P-\mathrm{GaAs}$ известна лишь для образцов, уровень легирования которых выше $10^{17} \mathrm{~cm}^{-3}\left[{ }^{11}\right]$. Эти значения ни в коем случае не удовлетворяют потребности в изучении диффузионной длины электронов в нелегированных слоях $P-\mathrm{GaAs}$, являющихся основой тиристора.

Для исследования диффузионной длины электронов были использованы тестовые $P^{+}-P-N^{+}$-структуры, которые изготовлялись методом выращивания из тонкого слоя раствора-расплава, $N^{+}$-эмиттер легировался Sn. Процесс наращивания $N^{+}$-слоя проводился по технологии, обеспечивающей сохранение профиля легирования $P$-области. Специального легирования $P$-области не проводилось и уровень легирования определялся фоновыми примесями и зависел от условий выращивания $\left[{ }^{6}\right]$. Толщина $P$-области составляла $100-200$ мкм. Разностная концентрация акцепторных и донорных примесей в $P$ - GaAs менялась от $10^{14}$ до $10^{17} \mathrm{~cm}^{-3}$.

Профиль легирования $P$-области определялся по вольт-емкостным характеристикам $P-N^{+}$-перехода и по вольт-емкостным характеристикам барьера Шоттки, создаваемого ртутным зондом по косому шлифу. 


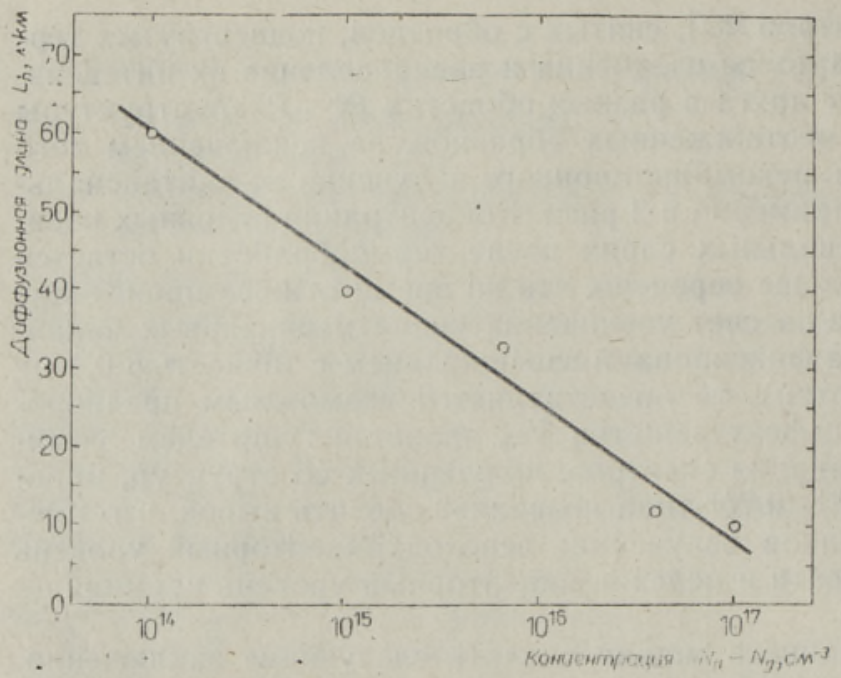

Рис. 2. Зависимость диффузионной длины электронов от разностной концентрации носителей в $P$-базе $P+-P-N$-структуры.

Измерение диффузионной длины осуществлялось в ходе исследования интенсивности фототока короткого замыкания на установке оптического лазерного зонда $\left[{ }^{12}\right]$. В качестве источника света использовался

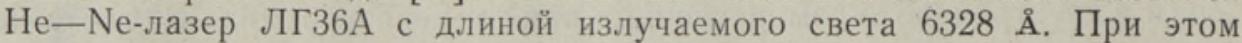
коэффициент поглощения излучения с данной длиной волны составлял $10^{4} \mathrm{~cm}^{-1}$, что позволяло исследовать диффузионные длины свыше 10 мкм.

Диффузионная длина электронов определялась на расстоянии $2-3$ диффузионных длин. Необходимо отметить, что для большинства образцов зависимость $\ln I / I_{0}=f(z)$ линейна при достаточном удалении от $P-N$-перехода. Кроме того, на этих же структурах измерялось время жизни электронов по методу Лэкса $\left[{ }^{19}\right]$.

Как видно из рис. 2, где приведена зависимость диффузионной.длины электронов от разностной концентрации носителей заряда в $P$ - GaAs, величина $L_{n}$ может достигать 60 мкм при концентрациях $10^{14} \mathrm{~cm}^{-3}$. Эти значения хорошо согласуются с данными $\left[{ }^{13}\right]$.

Данные измерений диффузионной длины также хорошо согласуются с данными по времени жизни, измеренными на этих же структурах при соответствующем уровне инжекции по методу Лэкса (при пересчете учитывалось снижение подвижности в нелегированном $P-\mathrm{GaAs}$ из-за сильной компенсации мелкими амфотерными примесями $\left.\left[{ }^{14}\right]\right)$.

Так, для концентрации легирующей примеси $8 \cdot 10^{15} \mathrm{~cm}^{-3} L_{n} \sim 35$ мкм. Вычисленное время жизни составляет 130 нс, а измеренное по методу Лэкса - 200 нс.

При концентрации $10^{14} \mathrm{~cm}^{-4} L_{n}$ достигала величины 60 мкм, что соответствовало $\tau_{n} \sim 360$ нс $\left(\mu_{n} \sim 3500 \mathrm{~cm}^{2} / \mathrm{B} \cdot \mathrm{c}\right)$, что хорошо согласуется со значением $\tau_{n}$, измеренным по Лэксу (400 нс).

Таким образом, значения диффузионной длины составляли $10-60$ мкм при изменении $N_{a}$ от $10^{17}$ до $10^{14} \mathrm{~cm}^{-3}$. Такие большие значения $L_{n}$ необходимо учитывать при изготовлении многослойных структур.

Влияние $L_{n}$ изучалось на примере триодной $N^{+}-P-N$-структуры, являющейся основой тиристора. Проводилось сравнение напряжения загиба $\left(U_{3 a r}\right)$ триодной $N^{+}-P-N$-структуры с напряжением пробоя $\left(U_{\text {проб}}\right) P^{+}-P-N$-структуры, созданной в этом же технологическом процессе и имеющей одинаковые параметры $P$ - и $N$-областей.

Зависимость отношения $\left(U_{\text {заг }} / U_{\text {проб}}\right)$ от то̊лщины нелегированной $P$-области $\left(w_{p}^{0}\right)$ описывается уравнением $\left[{ }^{18}\right]$ 
Рис. 3. Завнсимость напряжения загиба триодной $\mathrm{N}^{+}-\mathrm{P}-\mathrm{N}$-структуры от толщины $P$-базы. Кривая - теоретические, кружочки - экспериментальные данные.

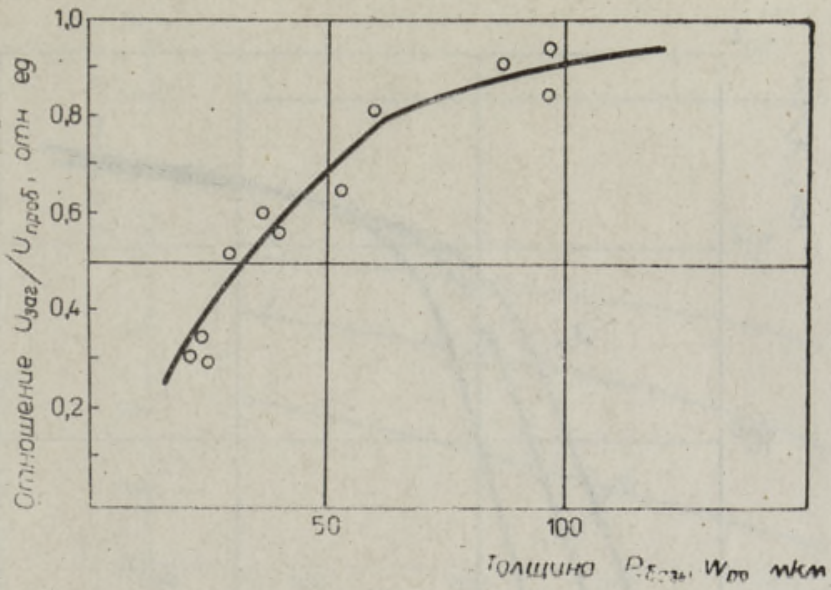

где $w_{p}^{0}-$ толщина нелегированной $P$-базы,

$\gamma_{n}$ - коэффициент инжекции,

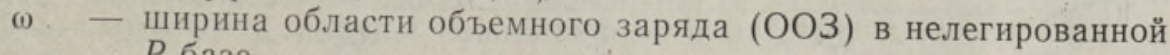
Р-базе,

$L_{n}$ - диффузионная длина электронов в $P$-базе,

$m$ - показатель, принимающий значения от 1 до 6.

На рис. 3 приведены экспериментальные значения $\left(U_{\text {заг }} / U_{\text {проб}}\right)$ для различных значений $w_{p}^{0}$ и рассчитанная по (1) зависимость

$$
U_{\text {заг }} / U_{\text {проб }}=f\left(w_{p}^{\circ}\right) \text {. }
$$

При расчете по (1) значение показателя $m$ принималось равным $3\left[{ }^{20}\right]$, коэффициент инжекции $\gamma_{n}=1$.

Значения ширины ООЗ прй напряжении загиба $\left(\omega\left(U_{3 a r}\right)\right)$ были получены по вольт-емкостным измерениям. Для каждого экспериментального образца исследовался профиль легирования (вольт-емкостным методом по косому шлифу). Соответствующее каждому экспериментальному образцу значение $L_{n}$ находилось из графика, приведенного на рис. 3.

Получено достаточно хорошее совпадение расчетных и экспериментальных значений. Это позволяет использовать экспериментальную зависимость $L_{n}$ от концентрации акцепторов при расчете напряжения переключения тиристоров.

3. Диоды Шоттки. Диоды с барьером Шоттки отличаются от силовых диодов с $P-N$-переходами малым прямым падением напряжения и высоким быстродействием. Выпускающиеся за рубежом кремниевые диоды с барьером Шоттки при токах $50-75$ А имеют прямые падения напряжения 0,5-0,7 В и работоспособны до 500 кГц.

Перспективным является создание диодов Шоттки на основе арсенида галлия $\left[{ }^{15}\right]$. При создании макетных образцов диодөв Шоттки использовали слои арсенида галлия $N$-типа проводимости толщиной $20-30$ мкм с концентрацией носителей тока $3-810^{15} \cdot \mathrm{cm}^{-3}$. Слои выращивались из газовой фазы на подложках ориентации (100) $3^{\circ}$, легированных теллуром до $1-2 \cdot 10^{18} \mathrm{~cm}^{-3}$. Барьер Шоттки создавался путем никелирования слоев. После никелирования к структурам припаивали термокомпенсаторы диаметром 0,67 см со стороны подложки и $0,31 \mathrm{cm-}$ со стороны барьера Шоттки. После пайки поверхность термокомпенсаторов защищали и с поверхности арсенида галлия стравливали свободный никель. После травления площадь поверхности барьера. Шоттки 


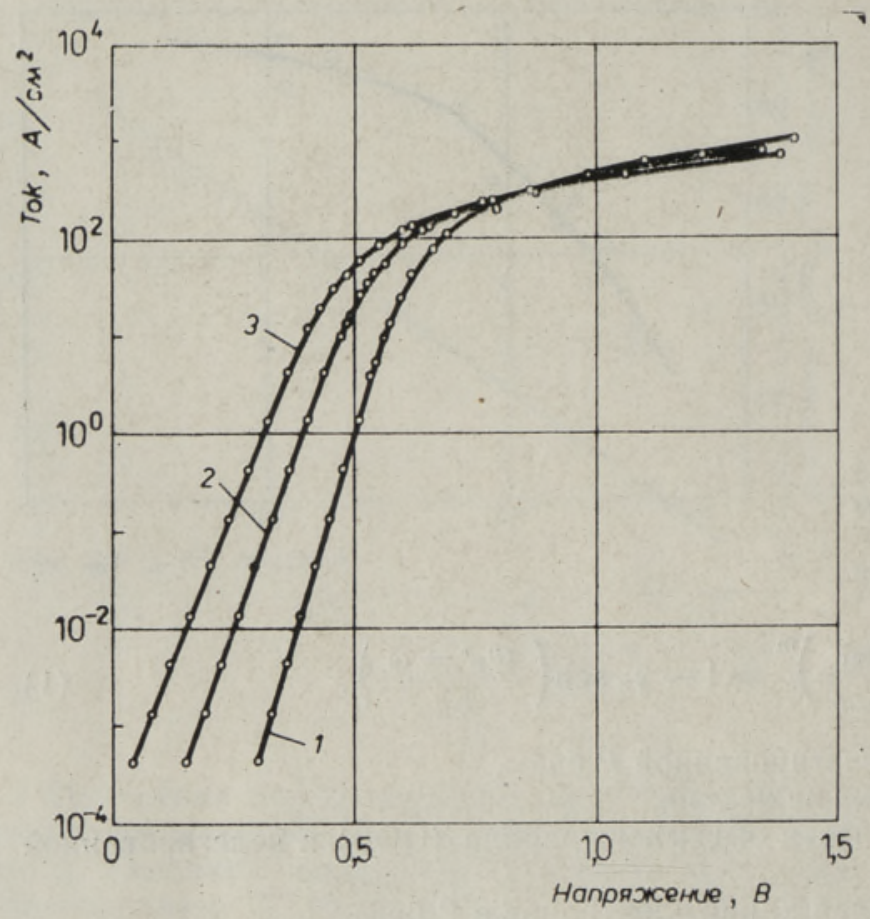

Рис. 4. Прямая ветвь вольт-амперной характеристики диода Шоттки. $l-T=273 \mathrm{~K}, 2=$
$T=348 \mathrm{~K}, 3-T=$ $=398 \mathrm{~K}$.

равнялась 0,076 см² $^{2}$. Далее структуры напаивали на основание диода и припаивали верхние выводы.

У полученных диодов были измерены:

прямые вольт-амперные характеристики (BAX) в интервале температур $273-400 \mathrm{~K}$ и плотностей тока $4 \cdot 10^{-4}-1,5 \cdot 10^{3} \mathrm{~A} / \mathrm{cm}^{2}$,

обратные ВАХ в интервале $273-473 \mathrm{~K}$,

вольт-фарадные $(C-V)$ характеристики на частоте 1 МГц при комнатной температуре.

Результаты измерений прямой ВАХ при разных температурах (рис. 4) аппроксимировались по формуле, описывающей величину плотности тока $(j)$ через барьер Шоттки

$$
j=A T^{2} \exp \left(-\frac{q \varphi}{k T}\right) \exp \left(\frac{q U}{n k T}\right)
$$

где $A-$ постоянная Ричардсона, $\mathrm{A} / \mathrm{cm}^{2} \cdot \mathrm{K}^{2}$,

$T$ - температура, K,

$K-$ постоянная Больцмана,

$q$ - заряд электрона, Кл,

$\varphi$ - высота барьера Шоттки, В,

$U$ - напряжение, приложенное к барьеру, В,

$n$ - коэффициент неидеальности.

Результаты измерений обрабатывались по методу наименьших квади,атов с помощью пакета программ АППРОКС $\left[{ }^{16}\right]$ на ЭВМ ЕС-1033. П мые ветви ВАХ полученных диодов в интервале плотностей тока $4 \cdot 10^{-4}-1,5 \cdot 10^{1} \mathrm{~A} / \mathrm{cm}^{2}$ линейны в координатах $\lg j-U$ (см. рис. 4) и хорошо аппроксимируются формулой (2). Если проанализировать формулу (2), то видно, что зависимость $U=f(T)$ имеет вид

$$
U \sim \alpha T \lg T^{2} .
$$

Зависимость линейна в координатах $U-T \lg T^{2}$ с коэффициентом наклона $-2,0 \cdot 10^{-4}$ Дж. Кл $\cdot \mathrm{K}^{-1}$, 
Рис. 5. Зависимость падения напряжения на диоде Шоттки от температуры при плотностях тока: 1 $1,3 \mathrm{~A} / \mathrm{cm}^{2}, 2-40 \mathrm{~A} / \mathrm{cm}^{2}$, $3-100 \mathrm{~A} / \mathrm{cm}^{2}, 4=$ $330 \mathrm{~A} / \mathrm{cm}^{2}$,

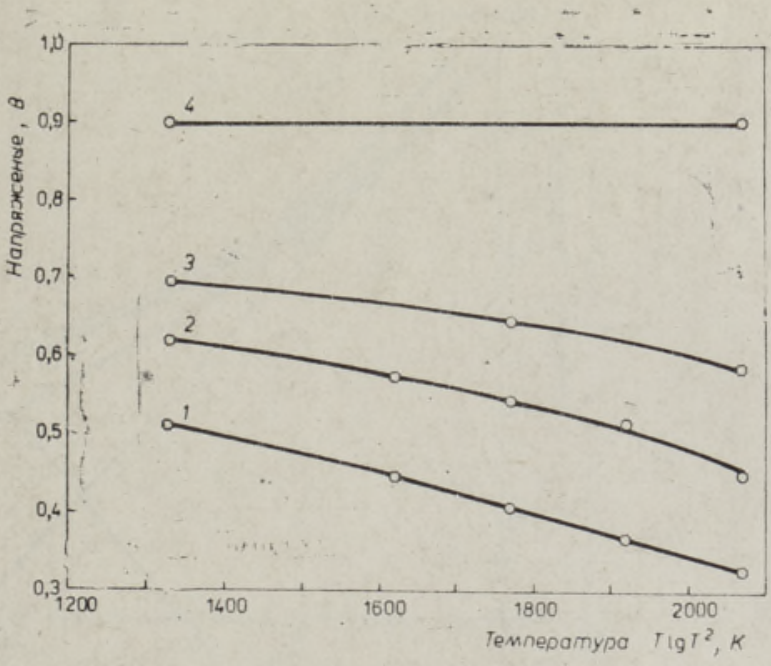

При анализе полученных экспериментально зависимостей падения напряжения на диоде Шоттки от температуры при плотностях тока 1,3 , 40,100 и $330 \mathrm{~A} / \mathrm{cm}^{2}$ (рис. 5) было обнаружено, что при малых плотностях тока зависимость линейна в координатах $U-T \lg T^{2}$ и имеет наклон $\left(\alpha=-2,5 \cdot 10^{-4}\right)$, хорошо совпадающий с рассчитанным из (3).

В результате анализа прямой ВАХ и зависимости $U=f(T)$ можно сделать вывод, что при плотности тока меньше $15-40 \mathrm{~A} / \mathrm{cm}^{2}$ все измеренное падение напряжения происходит на барьере Шоттки. Полученный переход имеет высокое качество. Коэффициент неидеальности равен 1,03 и соответствует лучшим значениям, описанным в литературе.

При повышении плотности тока начинает играть роль падение напряжения на последовательном сопротивлении эпитаксиального слоя и на омическом контакте с термокомпенсаторами. При плотностях тока 100 и $500 \mathrm{~A} / \mathrm{cm}^{2}$ падение напряжения на диодах Шоттки равно $0,66-0,70$ и $0,84-1,1$ В соответственно.

На основе результатов измерений $\mathrm{BAX}$ и $C-V$-измерений были рассчитаны высота барьера Шоттки и постоянная Ричардсона, средние значения которых соответствуют литературным данным $0,822 \pm 0,054 \mathrm{~B}$, $0,720 \pm 0,011 \mathrm{~B}$ и $3-127 \mathrm{~A} / \mathrm{cm}^{2} \cdot \mathrm{K}^{2}\left[{ }^{17,}{ }^{18}\right]$. Значения $\varphi$ и $A$ для каждого конкретного прибора имеют некоторые отклонения от среднего для всех приборов значения, но при этом хорошо коррелируют между собой (рис. 6). Их взаимосвязь может быть выражена эмпирической формулой

$$
\ln A=-20,60+28,52 \varphi \text {. }
$$

Величина обратного тока при малых обратных смещениях может быть выражена формулой

$$
j_{\text {обр }}=A T^{2} \exp \left(\frac{q \varphi}{k T}\right) .
$$

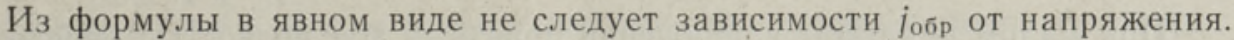
Но при приложении обратного напряжения высота барьера снижается, а ток соответственно растет (рис. 7 ).

Полученные ранее значения $A$ и $\varphi$ позволяют рассчитать величину обратного тока при разных температурах (рис. 7). Рассчитанные значения хорошо совпадают с измеренными, если их экстраполировать до нулевого обратного смещения.

В целом картина, видимо, следующая. Обратный ток перехода складывается из тока утечки по дефектам и поверхности перехода и тока, определяемого термоэлектронной эмиссией через барьер. 


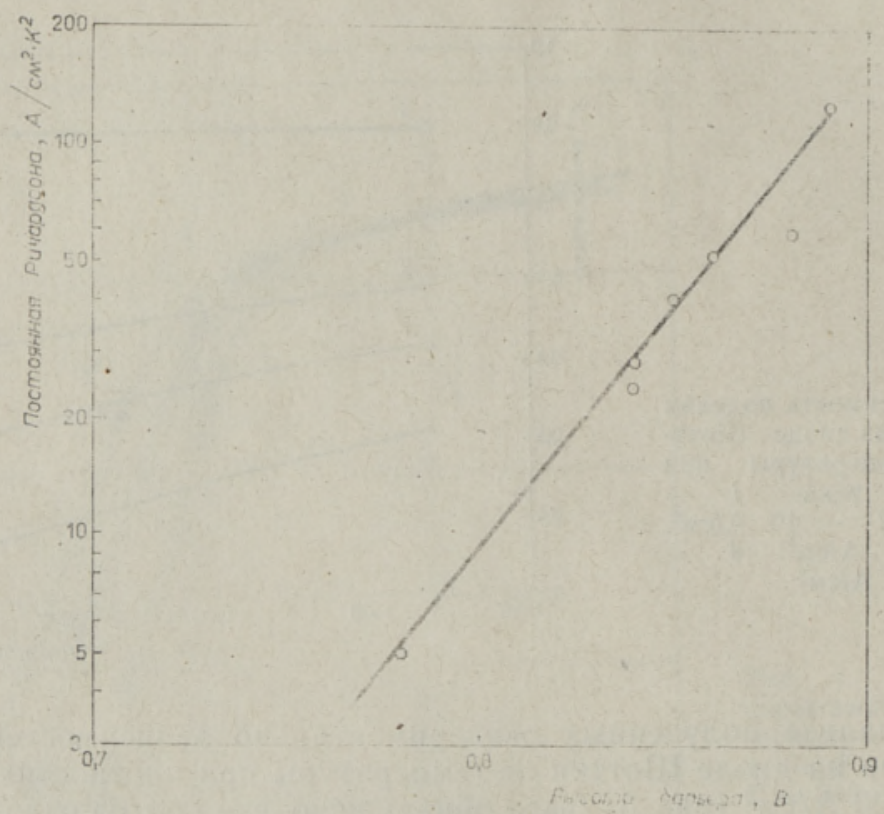

Рис. 6. Зависимость постоянной Ричардсона от высоты барьера Шоттки.

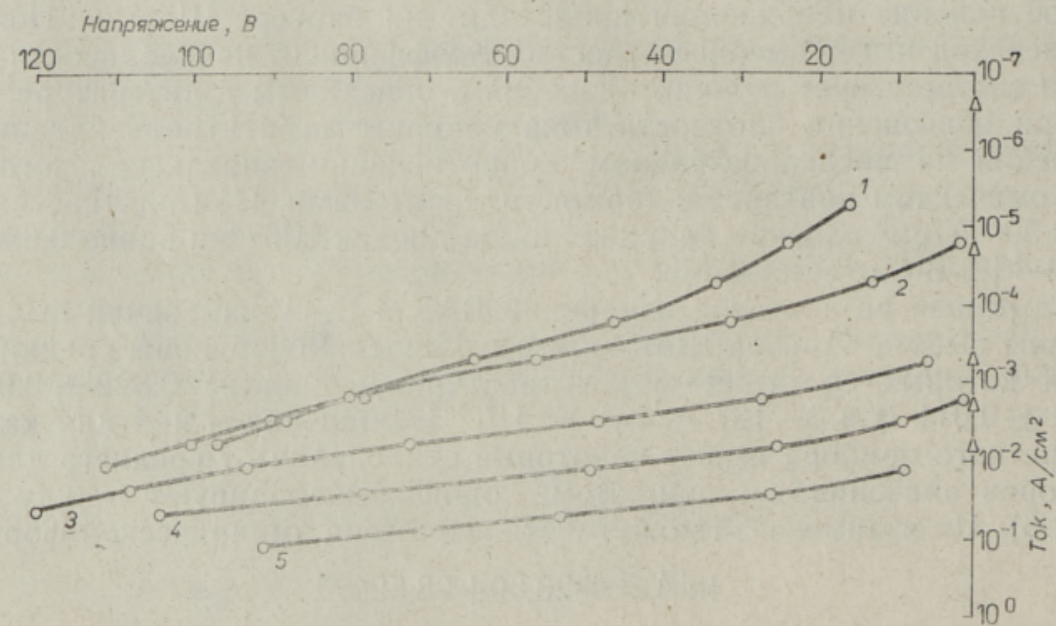

Рис. 7. Обратная ветвь ВАХ диода Шоттки при температурах: $1-323 \mathrm{~K}, 2-373 \mathrm{~K}, 3-423 \mathrm{~K}, 4-448 \mathrm{~K}, 5-473 \mathrm{~K} ; \triangle-$ pac, четные значения.

При малом обратном напряжении обратный ток полностью определяется второй составляющей й хорошо описывается формулой (5).

При больших смещениях и низкой температуре обратный ток определяется утечками по дефектам и поверхности перехода. Наблюдается сильная зависимость $j_{\text {обр } о т ~} U_{\text {обр. }}$

При повышении температуры ток по утечкам сохраняется, а ток, определяемый термоэлектронной эмиссией,. возрастает и становится

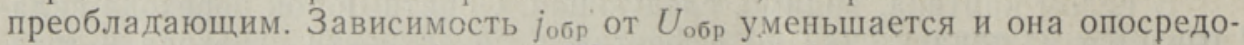
вана снижением высоты барьера Шоттки, 




Рис. 8. Зависимость плотности тока диода Шоттки от температуры при обратных смещеннях: $1-25 \mathrm{~B}, 2-50 \mathrm{~B}, 3-75 \mathrm{~B}, 4-$ расчетная зависимость при $U \leqslant 0,025 \mathrm{~B}$.

Это подтверждается и снятой экспериментально зависимостью $j_{\text {обр }}$ от температуры (рис. 8). Именно прй высокой температуре расчет лучше соответствует измеренным характеристикам.

Напряжение пробоя диодов при комнатной температуре достигало 145 В. Әто соответствует значениям, рассчитанным для лавинного пробоя резкого $P-N$-перехода.

Таким образом, показано, что путем никелирования эпитаксиальных слоев $\mathrm{GaAs}$ возможно создание силовых диодов Шоттки площадью $0,076 \mathrm{~cm}^{2}$. Полученные диоды имеют пробивные напряжения до 145 В и падения напряжения $0,66-0,7$ и $0,84-1,1$ В при плотностях тока 100 и $500 \mathrm{~A} / \mathrm{cm}^{2}$.

Свойства переходов соответствуют модели Шоттки для барьеров металл-полупроводник и в интервале плотностей тока $4 \cdot 10^{-4}$ $-1,5 \cdot 10^{1} \mathrm{~A} / \mathrm{cm}^{2}$ и температур $273-400 \mathrm{~K}$ хорошо описываются уравнением Шоттки (5).

\section{ЛИТЕРАТУ РА}

1. Аикинази Г. А. и др. Уч. зап. Тартуск. ун-та, вып. 466, 159-160 (1978).

2. Аикинази Г. А., Корольков В. И., Челноков В. Е. Снловые полупроводниковые прнборы на основе новых материалов (Tp. V Всесоюзного коордннационного совещания секции «Полупроводниковые гетероструктуры»). Таллин, 1979, 5-16.

3. Тучкевич В. М. ФТП, 1977, 11, № 11, 2065-2071.

4. Алферов Ж. Н. ФТП, 1977, 11, № 11, 2072-2083.

5. Ашкинази Г. А., Алферов Ж. И., Корольков В. И., Челноков В. Е. Электротехника, 1979, № 3, 4-7.

6. Золотаревский Л. Я. $и$ др. Распределение примесей в арсенид-галлиевых структурах большой площади, выращенных методом жндкостной эпитаксии (Tp. V Bceсоюзного координационного совещания секции «Полупроводниковые гетероструктуры»). Таллин, $1979,66-73$.

7. Борисова Л. А. В кн.: Процессы роста полупроводниковых кристаллов и пленок. Новосибирск, «Наука», 1981, 229-236.

8. Арсенид галлия. Получение, свойства и применение. (Под ред. Ф. П. Кесаманлы и Д. Н. Наследова). М., «Наука», 1973.

9. Аикинази Г. А. и др. Исследование некоторых параметров и характеристик арсенидгаллиевых диодных структур большой площади. (Тр. V Всесоюзного координационного совещания секции «Полупроводниковые гетероструктуры»). Таллин, 1979, 40-50. 
10. Аикинази Г. А., Киви У. М., Тимофеев В. Н. ФТП, 1981, 15, № 4, 718-723.

11. Shen, C. C., Pande, K. P.. Pearson, G. L. J. Appl. Phys.. 53. 2, 1982, $1236-1237$.

12. Саланди Х. К. Уч. зап. Тартуск. ун-та, вып. 466, $80-85$ (1978).

13. Nelson, R. J. Measurement of $100 \mathrm{~lm}$ minority carrier difiusion lenghts in $\mathrm{P}-\mathrm{GaAs}$ by a new photoluminescence method. -- Gallium Arsenide and Related Compounds 1978, Proc. 7th Int. Symp. 1979, 250்-262.

14. Гапоев А. Б., Никитин В. Г. В кн.: Технология полупроводниковых приборов. Таллин, «Валгус», 1982, 127-131.

15. Стриха В. И., Бузонева Е. В., Радзневский Н. А. Полупроводниковне приборы с барьерами Шоттки. М., «Советское радио», 1974.

16. Сотников Я. Д. В кн.: Пакеты прикладных программ САПР (Мат. Всесоюзного научно-технического совещания). Таллин, 1978, 150-155.

17. Tyagi, M. S. Surface Sci.. 64, № 1, 1974, 323.

18. Srivastova, A. K., Arora, B. M., Guha, S. Solid-State Electron, 24, 185-191 (1981).

19. Lax, B., Neustadter, S. F. J. Appl. Phys., 25, № 9, 1954, $1148-1154$.

20. Степаненко И. П. Основы теории транзисторов и транзисторных схем. М., «Энергия», 1973.

\section{Научно-исследовательский институт \\ Таллинского электротехнического завода им. М. Н. Калинина}

G. ASKINAZI, L. ZOLOTAREVSKI, V. TIMOFEIEV, L. MAZO,

M. SULGA, V. VOITOVITS, M. TAGASAAR, J. ORENSTEIN,

H. OORIKE, V. TSELNOKOV

\section{KÖRGTEMPERATUURILISED JA KORGSAGEDUSLIKUD GALLIUMARSENIIDIST JOUSEADISED}

Artiklis on näidatud, et galliumarseniidi baasil on vōimalik kōrgtemperatuuriliste kōrgsageduslike vōimsusdiodide, $t$ üristoride ja Schottky dioodide loomine, ning toodud nende parameetrid.

Nôrgalt legeeritud $P$ - ja $N$-tüüpi galliumarseniidist vedelike,pita:isia meetodil loodud baasiala dioodides ja türistorides on uuritud fotoluminestsentsi rieetodil ia määratud kaks maksimumi energiatega $1,507 \mathrm{eV}$ ja $1,487 \mathrm{eV}$. niis on seotud jääklisanditega.

On näidatud, et elektronide difusioonitee pikkus türistorstruktuuri nõrgaltlegeeritud p-baasis on $60 \mu \mathrm{m}$ aktseptorite kontsentratsioonil $10^{14} \mathrm{~cm}^{-3}$. On kindlaks määratud side elektronide difusioonitee pikkuse ja aktseptorite konisentratsiooni vahel nōrgaltlegeeritud $P$-GaAs-is.

On uuritud Schottky bảrjääri $\mathrm{Ni}-N$ GaAs-is ning mäăratud barjääri kōrgus ja Richardsoni konstant. Viimaste omavahelist sidet on kirjeldatud empiirilise valemiga.

On ära toodud Schottky dioodide päri- ja vastuvoolu voltamperkaraliteriatikud.

\section{G. ASHKINAZI, L. ZOLOTAREVSKY, V. TIMOFEYEV, L. MAZO \\ M. SHULGA, V. VOITOVICH, M. TAGASAAR, I. ORENSHTEIN, \\ H. OORIKE, V. CHELNOKOV}

\section{HIGH-TEMPERATURE HIGH-FREQUENCY GALLIUM ARSENIDE POWER DEVICES}

It has been shown that it is possible to fabricate high-temperatur high-frequency powe diodes, thyristors and Schottky diodes. Their parameters are given.

Structures of diodes and thyristors were investigated. Residua! impurities in P. and N-type high purity GaAs epitaxial layers grown by liquid phase epitaxy were studied. Low temperature photoluminescence technique was used to identify the impurities. The electron diffusion length in undoped P-type GaAs layers has been measured as a function of hole concentration. The measurements show that the diffusion length increases from $10 \mu \mathrm{m}$ at $\mathrm{P}=1 \times 10^{17} \mathrm{~cm}^{-3}$ to $60 \mu \mathrm{m}$ at $\mathrm{P}=1 \times 10^{14} \mathrm{~cm}^{-3}$.

The $\mathrm{Ni} / \mathrm{n}-\mathrm{GaAs}$ Schottky barrier junction has also been investigated. The height of the Schottky barrier and the Richardson constant were measured. They correlate following the given empirical formula. The current-voltage characteristics of Schottky diodes were studied. 